\title{
Las políticas sociales y el gobierno de la "población indígena". Estrategias y regulaciones en el multiculturalismo chileno
}

\author{
Rodrigo Agustín Navarrete-Saavedra \\ Doctor en Ciencias Humanas. Psicólogo \\ Universidad Austral de Chile. Valdivia, Chile \\ https:/ / orcid.org/0000-0002-3525-9595 • rodrigo.navarrete@uach.cl
}

\section{Resumen}

Este trabajo caracteriza estrategias y regulaciones que la política social multiculturalista de la postdictadura chilena promueve para los destinatarios "indígenas" en sus programas. Del análisis de un corpus de documentos de política social emanados de fuentes estatales, para-estatales y sub-estatales de etnogubernamentalidad, se infieren 4 conjuntos de estrategias y regulaciones, definidos como: marcaje, domesticación, tutela y puesta en valor, cada uno compuesto a su vez por subtipos más específicos. Se discute el modo en que dichas tecnologías reactualizan relaciones de colonialidad y la necesidad de problematizar este régimen y el papel asignado a los agentes de intervención social.

Palabras clave: Políticas sociales; Multiculturalismo; Poblaciones indígenas; Colonialidad.

Recibido: 31/07/2020 | Aprobado: 18/11/2020 |Publicado: 01/01/2021

(c) (i) (2) Esta obra está bajo una Licencia Creative Commons Atribución-NoComercialCompartirIgual 4.0 Internacional.

Financiación o proveniencia del artículo: artículo derivado de la investigación "Las políticas sociales y el gobierno de la población Mapuche en el multiculturalismo chileno de la posdictadura", realizada gracias a la beca de la Comisión Nacional de Ciencia y Tecnología, Conicyt, Chile. Folio No21130699.

¿Cómo citar este artículo? / How to quote this article?

Navarrete-Saavedra, R. A. (2021). Las políticas sociales y el gobierno de la "población indígena". Estrategias y regulaciones en el multiculturalismo chileno. Prospectiva. Revista de Trabajo Social e intervención social, (31), 345-368. doi: 10.25100/ prts.v0i31.8553. 
Navarrete-Saavedra

\title{
Social policies and the government of the "indigenous population". Strategies and regulations in Chilean multiculturalism
}

\begin{abstract}
This work characterizes strategies and regulations that the multiculturalist social policy of the Chilean post-dictatorship promotes for the "indigenous" recipients in its programs.

From the analysis of a corpus of social policy documents emanating from state, para-state and sub-state sources of ethnogovernmentality, 4 sets of strategies and regulations are inferred, defined as: marking, domestication, guardianship and enhancement, each one composed in turn by more specific subtypes.

The way in which these technologies reactivate colonial relations and the need to problematize this regime and the role assigned to the agents of social intervention are discussed.

Keywords: Social policies; Multiculturalism; Indigenous populations; Coloniality.

Sumario: 1. Introducción, 2. Metodología, 3. Hallazgos, 3.1 Marcaje, 3.2 Domesticación, 3.3 Tutela, 3.4 Puesta en valor, 4. Conclusiones, 5. Referencias bibliográficas.
\end{abstract}




\section{Introducción}

Con el final de la dictadura cívico-militar liderada por Pinochet (1973-1989) y el inicio de los gobiernos de transición democrática, el Estado chileno renuncia discursivamente al ideal de homogeneización cultural del pasado y asume oficialmente una política multiculturalista. No obstante, este multiculturalismo fue abandonando rápidamente el camino del reconocimiento y el estándar internacional de derechos indígenas (reconocimiento constitucional, ratificación de convenios como el 169 de la OIT, grados de autonomía política, derechos territoriales, administración de recursos naturales, etc.), decantando en un entramado de políticas sociales focalizadas para la superación de la "pobreza indígena"1. Al mismo tiempo se profundizan y expanden las lógicas mercantilistas, extractivistas y privatizadoras impuestas por la dictadura sobre los territorios indígenas, en línea con lo que ha sido denominado como "multiculturalismo neoliberal" (Assies, 2006; Boccara, 2007; Hale, 2004; Restrepo, 2012; Richards, 2016; ToledoLlancaqueo, 2007).

El artículo desarrolla algunos planteamientos críticos sobre las estrategias de regulación y las tecnologías de gobierno que la política social promueve sobre la "población indígena" 2 , argumentos que se originan en un proceso de investigación sociohistórica que tuvo por objetivo problematizar el papel que las políticas sociales han jugado en el multiculturalismo chileno de la posdictadura. Por la extensión y características propias del estudio no se pretende dar cuenta detallada de los resultados ni profundizar en las fuentes documentales que conforman el corpus de análisis. La opción escogida en su lugar es presentar y caracterizar de forma bastante más acotada y simplificada los cuatro conjuntos de estrategias identificadas en el proceso.

Teóricamente se trata de extender herramientas de la analítica foucaultiana de gobierno de las poblaciones (Foucault, 2012) hacia la nueva cuestión social y la nueva cuestión étnica, pero apropiada desde un posicionamiento latinoamericanista y una sensibilidad decolonial. En este marco el multiculturalismo y sus políticas pueden ser entendidos como un particular diagrama de saber/poder, una nueva racionalidad de

1 Según la encuesta CASEN (encuesta de caracterización socioeconómica) de 1996 el 35,6\% de la población indígena en Chile vivía en condición de pobreza, mientras para la población no indígena ésta solo afectaba al 22,7\%, es decir, una brecha de 12,9 puntos. Para la CASEN 2015 la pobreza alcanzaba al 18,3\% de la población indígena y al 11,0\% de la población no indígena (Instituto Nacional de Estadísticas Chile, 2005; Ministerio de Desarrollo Social Chile, 2017a). Más allá de los datos duros, existe un discurso, encabezado por el Banco Mundial, que ha sido crucial para enmarcar la cuestión indígena de las últimas décadas como un problema de pobreza y grupos vulnerables. Véase La pobreza indígena en el discurso del Banco Mundial (Navarrete-Saavedra, 2018).

2 En este trabajo se utiliza la expresión población indígena entre comillas, pues reducir un pueblo a una población es precisamente un rasgo fundamental del lenguaje de la gubernamentalidad en el sentido foucaultiano. 
gobierno de las poblaciones marcadas en clave étnica que busca alinear la subjetividad y conducta de los gobernados con los fines de gobierno sin necesidad de coerción (Laval y Dardot, 2013; Murillo, 2008; Powell \& Steel, 2012; Rojas-Lasch, 2012). Se trataría de un nuevo modo de gestión de la alteridad y recorte del cuerpo social en clave étnica, con la finalidad de constituir los cuerpos y comunidades indígenas en sujetos y objetos de gobierno (Álvarez-Leguizamón, 2002, 2011; Bascopé-Julio, 2009; Boccara, 2007; Boccara y Bolados, 2010).

\section{Metodología}

Consistente con una aproximación desde la analítica de la gubernamentalidad, los hallazgos presentados no tienen que ver con lo que los sujetos focalizados empíricamente por la política social hacen o dicen, sino que se trata de develar desde los discursos de dominio público -con un grado importante de libertad interpretativa del analista- la racionalidad, las tecnologías y las estrategias desplegadas para gobernarlos (Spink y Menegón, 2006). Se trata, por lo tanto, de desplazar el foco de interrogación desde los sujetos/comunidades hacia los mismos dispositivos institucionales y los aparatos cognitivos de gobierno que permiten la construcción de la "población indígena" como objeto de conocimiento especializado e intervención social. Siguiendo al sociólogo alemán Ulrich Bröckling, para estas aproximaciones interesa "la corriente que empuja a las personas en una dirección y no hasta donde se dejan llevar, cómo la utilizan para avanzar o cómo tratan de evitarla o nadan contra ella" (Bröckling, 2015, p. 22). Así, se intenta además acoger los debates tanto sobre la crisis de representación y la imposibilidad de hablar por el otro, como sobre los conocimientos situados y las relaciones de colonialidad en la investigación social (Corona y Kaltmeier, 2012; Huinca-Piutrin, 2012; Nahuelpán, 2013; NavarreteSaavedra, 2015; Tuhiwai-Smith, 2016; Tuider, 2012).

Concretamente, se trata de una investigación documental de carácter sociohistórico (el período abarcado va desde 1989 a 2015)³ cuyo corpus de análisis se conformó de documentos de dominio público (Rapley, 2014) vinculadas genéricamente al Ministerio de Planificación y Desarrollo (MIIDEPLAN), posteriormente denominado Ministerio de Desarrollo Social, tales como el Programa Orígenes, el Programa Chile Indígena, el Plan Araucanía, el Sistema Chile Solidario-Puente, el Programa Ingreso Ético Familiar. Algunos de estos programas se focalizan en los individuos, familias y comunidades exclusivamente en su calidad de "indígenas", mientras otros lo hacen en su condición de "pobres". La selección de unidades de análisis no tiene que ver, por lo tanto, con un muestreo de sujetos representativos de una población, sino con un "muestreo documental" (Flick, 2012) donde

3 Las administraciones del aparato estatal incluidas en esta revisión son: 1989-1994 (Patricio Aylwin, Concertación), 1994-2000 (Eduardo Frei, Concertación), 2000-2006 (Ricardo Lagos, Concertación), $2006-2010$ (Michelle Bachelet, Concertación), Sebastián Piñera (2010-2014, Coalición por el cambio), 2015-2018 (Michelle Bachelet, Nueva Mayoría). 
lo que se busca son discursos fijados en archivos. Se incluyen en este proceso fuentes estatales, pero también para-estatales (ONG's, ejecutores, consultoras) y no estatales (prensa, estudios de universidades, etc.) pues la gubernamentalidad, en términos foucaultianos, no puede ser entendida como propiedad exclusiva del Estado ni éste como su único origen, más bien se trata de una racionalidad que fluye y atraviesa el aparato estatal, proveniente de múltiples y diversas fuentes.

Los resultados que acá presentamos corresponden a una línea específica de indagación dentro de una investigación más amplia. Los criterios de calidad que un estudio cualitativo como este puede garantizar tienen que ver con la credibilidad y la auditabilidad. La credibilidad se ha garantizado a través de un compromiso prolongado de exposición a los datos, la construcción de un robusto corpus de análisis y estrategias de triangulación en diversos momentos del proceso. Por su parte, la auditabilidad tiene que ver con hacer transparente la producción de datos, las técnicas y procedimientos empleados en su tratamiento, visibilizando los documentos de análisis, los pasos del analista y sometiendo las decisiones metodológicas escogidas al juicio de expertos (Flick, 2014; Vasilachis de Gialdino, 2006). De todos modos, se reconoce que para identificar estrategias y efectos regulatorios desde un corpus textual sociohistórico amplio, es necesario defender una aproximación abiertamente interpretativa, que ofrezca grados importantes de libertad para el analista.

Consideramos que es posible organizar las estrategias de regulación y las tecnologías que las políticas sociales multiculturalistas de la posdictadura chilena implementan sobre la "población indígena" en cuatro conjuntos denominados: marcaje, domesticación, tutela y puesta en valor. Junto con caracterizar cada uno de estos conjuntos, describiremos algunos subtipos, efectos o formas más específicas en cada caso.

\section{Hallazgos}

Previo a la presentación de las regulaciones específicas, es necesario contextualizar el período revisado (1989-2015) para poder situar dichas regulaciones dentro de ciertas configuraciones o matrices sociohistóricas más amplias. De este modo, proponemos 3 grandes formaciones o matrices identificables en el período revisado: a) una matriz de la diferencia/reconocimiento. Es la matriz discursiva inaugural de la postdictadura y del multiculturalismo chileno (central en la década de los años noventa), caracterizada por un discurso transversal de admitir la existencia de una diversidad negada y de avanzar en políticas de reconocimientos; b) una matriz de la vulnerabilidad/protección, que viene a acotar, limitar y reducir la promesa de reconocimiento/derechos hacia un problema de pobreza étnica y políticas focalizadas; c) una matriz de la activación/oportunidades que propone reemplazar las políticas de la vulnerabilidad/protección por nuevas políticas del emprendimiento y la habilitación para competir, claramente identificable desde la 
implementación del Programa Orígenes en la década del 2000 (Lagos-Bachelet) y, con toda propiedad, con el Plan Araucanía y la administración Piñera (Navarrete-Saavedra, 2019). De este modo, las diferentes regulaciones descritas a continuación se corresponden totalmente o cobran mayor énfasis dentro de alguna de estas matrices discursivas.

\subsection{Marcaje}

Abandonando la aspiración universalista de las políticas sociales del modelo bienestarista, de providencia o desarrollista, la focalización neoliberal demanda nuevas técnicas de observación y marcaje para constituir los grupos legítimamente destinatarios de intervención estatal (target groups). En el caso de las políticas multiculturalistas el marcaje se realiza en clave étnica, es decir, son las identidades étnicas reconocidas por el Estado las que conforman un código de distinción básica de la población. En primer lugar, se trata de la distinción entre población "indígena" y población "no indígena" y luego, más específicamente, en la pertenencia a alguno de los pueblos (etnias) "originarios" reconocidos legalmente 4 . Se trata de la puesta en marcha de la "máquina culturalista" estatal que interpela directamente a la población a definirse en términos étnicos, una especie de reetnificación, desplazando otros clivajes utilizados en el pasado como ocupación e identidad de clase (Bascopé-Julio, 2009). El sujeto de intervención de la política social multiculturalista debe estar étnicamente marcado para organizar la acción correspondiente.

Dentro de esta estrategia de marcaje en el cual participa la política social identificamos dos posibles efectos que denominamos como exotización/nativización y estigmatización. Con exotización/ nativización lo que se pretende mostrar es que el marcaje étnico conlleva prácticas y efectos de regulación en la línea de sobrevisibilizar la diferencia y promover una representación del sujeto indígena como "exótico" y "nativo" a través de generalizaciones, estereotipos y simplificaciones. En las políticas sociales comprometidas con la estrategia de desarrollo basada en el turismo de intereses especiales, turismo cultural o etnoturismo, estas tecnologías son evidentes, pues sin sujetos nativos y sin prácticas exóticas dichas apuestas carecerían de sentido: "vive una experiencia inolvidable durmiendo y cocinando en una ruca en el Lago Budi, cerca de Temuco. ¡No pierdas la oportunidad de conocerlo!" o "Prueba su exquisita gastronomía, convive con sus costumbres y experimenta una conexión mágica con estos pueblos que hasta el día de hoy conservan sus tradiciones" (Chile Travel, 2014). Con la exotización/nativización se ofrece un reconocimiento de la "alteridad" y la "diferencia" alternativo a la inferiorización, animalización y barbarización de los indígenas

4 En el censo de 1992 sólo se consideró a 3 pueblos indígenas (Mapuche, Aymara y Rapa Nui). En el censo de 2002 la pregunta fue reformulada así: “ ¿Pertenece usted a alguno de los siguientes pueblos originarios o indígenas?” Y las opciones eran: "alacalufe (kawaskar), atacameño, aymara, colla, mapuche, quechua, rapanui, yámana (yagán), ninguno de los anteriores". Véase Estadísticas Sociales de los pueblos indígenas en Chile, Censo 2002 (Instituto Nacional de Estadísticas Chile, 2005, p. 8). En Chile hasta el día de hoy no existe reconocimiento constitucional de los “pueblos indígenas", sino solamente como "etnias" originarias. Ver también Ley 19.253 de 1993. 
propia de la matriz moderno/colonial de poder y su legado (Quijano, 2000), dando paso a esta versión que amplifica la distancia e inconmensurabilidad entre la sociedad dominante y las minorías que ahora pueden ser toleradas ${ }^{5}$.

La estigmatización, por su parte, es un efecto reconocido y observado de las políticas sociales focalizadas que operan a través del marcaje en clave de vulnerabilidad (podríamos decir que es un efecto no deseado de la política social). CIEPLAN 6 reconocía ya en los años noventa que "el costo de la estigmatización social parece más fuerte en los programas que asumen mecanismos de focalización apoyados en la demanda y cuya unidad es el individuo o la familia, puesto que, para acceder al beneficio, los beneficiarios deben reconocer y hacer pública su pobreza, lo que generalmente es visto como una humillación, que frena la demanda por el beneficio al cual se tiene derecho" (Raczynski, 1994, p. 220). Al abandonar el discurso de derechos sociales y universalización de servicios básicos y desconectar la situación de la población indígena de procesos históricos de violencia y despojo racialcolonial, explotación económica y desempoderamiento político, la política focalizada interpela a los sujetos a reconocerse como destinatario de los programas sociales que los constituyen como tales desde la negatividad, la carencia, la debilidad, la desventaja.

\subsection{Domesticación}

Se trata de un conjunto de estrategias desplegadas desde la etnogubernamentalidad que sitúan o enmarcan ciertos usos de la política social con un carácter marcadamente disciplinario, para contener y disminuir el potencial riesgo y peligro que estas poblaciones acarrean para el cuerpo social. En esta línea hemos identificado tres tipos más específicos de regulaciones que han sido conceptualizadas como: pacificación, despolitización y psicologización.

Por pacificación se propone entender el uso sistemático de la política social dentro del marco de securitización de la gubernamentalidad étnica, es decir, cuando la política social cobra protagonismo en la desactivación de situaciones de conflictividad social o, metafóricamente, como brazo izquierdo que complementa el brazo derecho de política punitiva de criminalización respecto de las mismas "poblaciones"7. La instalación del

${ }^{5}$ La exotización y la inconmensurabilidad son, siguiendo a autores como Said o Sousa Santos, estrategias de representación del Otro propias de Europa respecto de Oriente y sus poblaciones, diferentes de la inferiorización, animalización y barbarización que se ha asignado a los "indígenas" y "negros" desde dicha matriz moderno/colonial de poder. Ambas representaciones son constitutivas de modalidades diferentes de racismo.

6 CIEPLAN es un centro de estudio donde se instala buena parte de la intelectualidad de oposición a la dictadura de Pinochet y será el centro neurálgico de gestación de las políticas económicas y sociales de los primeros gobiernos de la transición.

7 Acá claramente estamos pensando en el caso de las resistencias, demandas y movilizaciones de comunidades Mapuche en el centro-sur de Chile, frente a las cuales el Estado ha promovido una política punitiva de militarización, criminalización y judicialización. 
Programa Orígenes, en buena medida, CONADI y el Fondo de Tierras ${ }^{8}$ durante bastantes años, son ejemplos de un uso selectivo de la política social con fines de pacificación de conflictos sociales emergentes. Para Ramírez (2015) desde Libertad y Desarrollo, el objetivo estratégico de los gobiernos de la Concertación fue el de "tierra por paz" (p. 14) $)^{9}$. No cabe duda de que este papel de pacificación de las relaciones sociales es un componente esencial del espíritu de las políticas sociales modernas (Illanes, 2007 y Lautier, 2008), lo que no quita la necesidad de subrayarlo y describirlo específicamente dentro de esta nueva generación de políticas sociales focalizadas y diferenciadas en clave étnica. Este uso de las políticas sociales en el multiculturalismo chileno ha sido además descrito por diversos analistas (Hale, 2004; Hale \& Millamán, 2005; Richards, 2016; Toledo-Llancaqueo, 2007).

Con despolitización nos referimos a la sustracción de los problemas sociales abordados desde la política social de la matriz del antagonismo social donde tuvieron su origen, para llevarlas al campo exclusivamente técnico. La "pobreza indígena" representa un caso paradigmático de abordaje de un problema social borrando cualquier referencia sistemática al despojo de recursos materiales y simbólicos, al desempoderamiento político y la desestructuración del mundo indígena por el colonialismo interno o a un modelo de desarrollo extractivista depredador de recursos naturales, para trasladarlo a un espacio aséptico de mediciones, estadísticas, cifras oficiales y focalización de políticas diseñadas en oficinas centralizadas en Santiago. El gesto que nos interesa destacar acá tiene que ver con suprimir la posibilidad de los propios sujetos colectivos de diagnosticar sus problemas e identificar sus causas estructurales e históricas, locales y globales y, al contrario, ofrecer un diseño estandarizado y altamente tecnificado, basado principalmente en cifras, que concentra el saber del lado de las instituciones y los expertos.

Esta despolitización implica la reducción de la capacidad de agencia de los sujetos y comunidades indígenas respecto de los problemas que los afectan directamente, dejándolos

8 El Programa Orígenes es un programa multifase destinado a la superación de la pobreza indígena implementado durante toda la década del 2000. Se financia con un préstamo del Banco Interamericano de Desarrollo y un aporte estatal. CONADI es la Corporación Nacional de Desarrollo Indígena, organismo estatal responsable de gestionar políticas hacia los pueblos indígenas y que cuentan con un grado limitado de participación de éstos a través de la elección de sus consejeros. El Fondo de Tierras es el mecanismo que han implementado los gobiernos de la posdictadura para la entrega de tierras a comunidades que tienen demandas históricas por despojo y usurpación. El mecanismo es de postulación, compra y asignación de tierras, es decir, no hay expropiación estatal hacia los latifundistas o particulares que se apropiaron indebidamente de dichas tierras, sino que se utilizan procedimientos de mercado. Algunos de los documentos revisados para sostener estas interpretaciones son: Ministerio de Desarrollo y Planificación-Corporación Nacional de Desarrollo Indígena (2010), Ministerio de Planificación y Desarrollo y Banco Interamericano de Desarrollo (2001), Ministerio de Desarrollo Social Chile (2012) y Ministerio de Desarrollo Social Chile (2013b).

9 No obstante, el diagnóstico de Libertad y Desarrollo (Centro ideológico de la derecha y del gobierno de Sebastián Piñera) es que dicha política ha sido un fracaso y que la compra de tierra ha ido de la mano con una escala de violencia. En los hechos, el gobierno de Sebastián Piñera congeló la política de tierras a las "115 comunidades priorizadas", casos que ya venían comprometidos de la administración anterior. 
o como simples beneficiarios pasivos (en las políticas sociales de protección) o como "contrapartes" o "socios" (en las políticas del emprendimiento social) que deben disponer de su capital humano y social en proyectos e iniciativas que si bien requieren de su compromiso personal, están orientadas a finalidades que no pueden ser discutidas por los propios sujetos o comunidades. En ambos casos se trata de gestionar la "pobreza indígena" como problema autorreferencial, cuyo abordaje requiere intervención sobre los propios sujetos que viven dicha situación y no, por ejemplo, a nivel de las relaciones sociales de poder, la distribución de la riqueza o la gestión de los territorios y sus recursos naturales. Por ejemplo, el Programa Orígenes ${ }^{10}$, el Programa Puente o las medidas del Plan Araucanía (Gobierno de Chile, 2010) suprimen discursivamente las demandas históricas más reconocidas del movimiento mapuche: recuperación de tierras, control sobre territorios y gestión de recursos, empoderamiento efectivo con mayores niveles de autonomía política local, etc. y nos retrotraen hacia el individuo, la familia o la comunidad como unidad de intervención y depositaria en sí misma del problema, ya sea por su diferencia cultural que los hace vulnerables a ser rezagados o afectados negativamente por los procesos de desarrollo, ya sea por el escaso aprovechamiento y gestión de las propias capacidades, recursos y capitales intangibles del sujeto/comunidad disponibles para el emprendimiento.

Por último, está la arista de la psicologización, con la cual se espera significar más detalladamente este preciso desplazamiento que promueven las políticas sociales de última generación, incluidas las de corte multiculturalista, al reducir los problemas sociales a dilema de estatus psicológico individual. En los programas sociales de nuestro interés (Orígenes, Chile Indígena, Puente, IEF y otros) esta psicologización se produce al eliminar discursivamente las relaciones sociales de poder y los condicionantes estructurales del empobrecimiento de la "población mapuche" y volcar una parte importante de la atención

\footnotetext{
10 En el caso de Orígenes podemos encontrar el "Subprograma de Desarrollo Integral de Comunidades Indígenas" cuyo objetivo es "fortalecer a las comunidades indígenas en su capital humano, social, cultural, natural, físico y patrimonial" (Ministerio de Desarrollo y Planificación-Corporación Nacional de Desarrollo Indígena, 2010, p.16). Este subprograma está compuesto por el componente de "fortalecimiento de comunidades y organizaciones indígenas" que contempla los subcomponentes de "planificación participativa" y de "fortalecimiento organizacional". Contempla capacitación amplia en "planificación, elaboración y presentación de propuestas"; "administración, gestión, seguimiento y evaluación de proyectos"; "conocimiento del Estado y difusión de la oferta de los programas y recursos ofrecidos por los servicios públicos y privados para el desarrollo local"; "comunicación y liderazgo"; "control de gestión"; "generación de redes sociales" (Ministerio de Desarrollo y Planificación-Corporación Nacional de Desarrollo Indígena, 2010, pp. 16-17). Todo esto podemos ubicarlo en la dirección hacia abajo, hacia las comunidades y el fortalecimiento de sus capacidades, mientras el segundo subprograma se orienta a la "Oferta pública culturalmente pertinente", que pretende institucionalizar una "oferta pública pertinente y adecuada a la realidad sociocultural de las comunidades indígenas" (Ministerio de Desarrollo y Planificación-Corporación Nacional de Desarrollo Indígena, 2010, p. 17). Este componente apuntaría hacia "arriba", a la red de oportunidades o espacio del mercado donde deben desenvolverse los sujetos con sus capitales tangibles e intangibles. No hay ningún objetivo ni componente del Programa Orígenes que responda a las demandas históricas del movimiento mapuche: tierra/territorio, empoderamiento político y mayores niveles de autonomía.
} 
Navarrete-Saavedra

y del lenguaje institucional hacia "abajo", hacia la "responsabilización de los sujetos" para superar la condición de pobreza. La psicologización es, por lo tanto, una tecnología para direccionar las atribuciones y responsabilidades sobre los problemas sociales, eludiendo explicaciones de causalidad estructural y promoviendo sistemáticamente atribuciones internas, centradas en las disposiciones de los sujetos. El discurso, por ejemplo, del Programa Araucanía Tierra Viva, sostiene que se trata de pasar desde la discusión sobre lo que no se tiene (tierra, derechos, reivindicaciones), hacia una nueva lógica de "cuidado y buen uso de lo que se tiene" (Van-Immerzeel, 2005, p. 37). El énfasis recae en "competencias blandas" de los propios sujetos en situación de vulnerabilidad o pobreza (aprendizaje, motivación, coraje, ingenio). Se trata de la "gestión del conocimiento campesina e indígena" y de "desarrollar la capacidad de aprender" (p. 37). Por este motivo es que la psicologización a la que nos referimos es una tecnología antisocial o, mejor dicho, desocializadora. Dicha desocialización de la pobreza se conduce en políticas que no tocan ninguna variable vinculada con la redistribución de riqueza, medios de producción u otros bienes materiales y simbólicos, sino simplemente predican la activación/motivación del sujeto -en el caso indígena este sujeto también puede ser comunitario-, "lograr la activación de las comunidades organizadas" (Ministerio de Desarrollo Social Chile, 2017b, p. 15) y disponer de un entorno de oportunidades vía proyectos y nichos de negocios; el "entorno de oportunidades públicas y privadas con pertinencia cultural".

\subsection{Tutela}

Se trata de que el subgrupo de la población que es marcada en clave étnica como beneficiaria de política focalizada queda bajo algún tipo, relativamente flexible y liviano, de tutelaje individual y/o familiar en función de su propio beneficio. Estas tecnologías de tutelaje ya no se dan en instituciones disciplinarias cerradas, como en el modelo panóptico tan bien descrito por Foucault para la modernidad clásica, sino de modo mucho más interactivo, a modo de una red, en espacios públicos o en los propios domicilios, a través de canales participativos, casi siempre formalmente "voluntarios", es decir, sin la coacción y obligación de la intervención social normalizadora. El tutelaje implica, entonces, una tecnología que generalmente se materializa a través de un agente de intervención directa, en visitas domiciliarias o talleres en sedes de la propia comunidad o alguna institución y requiere de una relación cara a cara entre el agente y el individuo/familia/grupo de personas focalizado. Dentro de estas tecnologías tutelares hemos identificado 5 formas específicas de regulación etiquetadas como: vinculación afectiva, condicionamiento/compromiso, infantilización, management/coaching social y burocratización.

Respecto de la vinculación afectiva, esta aparece como un requisito de la intervención psicosocial, pues implica una relación directa, cara a cara entre un agente externo y un sujeto beneficiario, relación que debe promover un grado de confianza y estabilidad para sostener 
la intervención y aumentar las probabilidades de éxito. Tal como lo declara la propia Ley 19.949 que crea el Sistema de Protección Social Chile Solidario, el apoyo psicosocial consiste en un "acompañamiento personalizado a los beneficiarios incorporados a Chile Solidario, por parte de un profesional o técnico idóneo, con el objeto de promover el desarrollo de las habilidades personales y familiares necesarias para satisfacer las condiciones mínimas de calidad de vida" (Ley 19.949 de 2004, p. 2). Dicha intervención psicosocial se caracteriza por el tipo de vinculación que se busca establecer entre el agente externo y la familia, el cual requiere de un acercamiento al espacio más íntimo del hogar, mediante la visita domiciliaria, en los casos del Programa Puente y del Ingreso Ético Familiar. En este sentido es que se puede señalar que se recupera una tradición inaugurada a inicios del siglo $X X$ con las visitadoras sociales y su papel de mediación entre la institucionalidad y el mundo popular (Illanes, 2007). Con el Programa Puente se trata de una política que llega a las familias indígenas en su condición de extrema pobreza, utilizando la vinculación afectiva del mediador (apoyo familiar) para establecer y sostener los compromisos que la familia debe realizar para ser conectada con sus "derechos" (redes sociales y beneficios que están a su disposición) y recibir los bonos condicionados, de igual manera como sucede con el resto de las familias en extrema pobreza del país.

Justamente esta estrategia de transferencias condicionadas que inaugura el Programa Puente y que profundiza el Ingreso Ético Familiar es lo que identificamos como estrategia de condicionamiento/compromiso, mediante la cual se busca el disciplinamiento y la moralización de los comportamientos de las familias focalizadas. Al condicionar el pago de bonos o transferencias monetarias al cumplimento de compromisos, se relativiza el carácter de "derecho" que la retórica de la protección intenta instalar en la política social. Se trata de un intercambio tremendamente desigual, que apela a la vinculación afectiva entre el mediador y la familia (o la mujer como representante de la familia), donde se intenta apelar a una norma de reciprocidad casi interpersonal -el compromiso es suscrito entre la mujer representante del hogar y el mediador- pero donde detrás de dicha apariencia de relación interpersonal lo que hay es una finalidad institucional predefinida, ajena a los sujetos del intercambio, que debe ser aceptada y actuada por éstos. Se trata, por lo tanto, de una tecnología que instrumentaliza ciertas normas de interacción interpersonal, reciprocidad y vinculación afectiva, para condicionar los comportamientos de las familias focalizadas. En el caso del Programa Puente, se trata de una verdadera lista de instrucciones conductuales que deben observarse y regularse en las familias. Por ejemplo, cuando el Programa Puente requiere que el apoyo familiar (agente externo) observe y fomente tareas como "hacer las camas", "mantener el aseo", "lavar la loza" en la familia, se está asociando las tareas domésticas con la superación de la pobreza extrema (objetivo del programa), como si el nivel de ingreso de las familias dependiera de cómo sus miembros distribuyen y realizan estas tareas domésticas. En la llamada Observación Psicosocial de Habitabilidad el apoyo familiar Puente debe preguntarse si “ ¿los miembros de la familia tienen una buena higiene 
personal?”, “ ¿se encuentran las camas hechas, la loza lavada, el baño y la cocina limpia, los utensilios y otros objetos ordenados?" 11 .

En las familias acomodadas jamás se problematiza si sus integrantes "hacen sus camas", "mantienen el aseo", "lavan la loza", y si eso guarda relación con la situación socioeconómica de la familia pues, de hecho, son tareas que las familias acomodadas no suelen realizar, sino que pagan a otros para que las realicen por ellos (trabajo doméstico). Es decir, este condicionamiento/compromiso opera también reforzando estereotipos y prejuicios respecto de los modos de ser de los integrantes de las familias en situación de pobreza lo que, en función del énfasis puesto sobre las tareas domésticas, el aseo y la higiene, podríamos sintetizar en la idea de que los pobres, y los indígenas pobres por extensión (y tal vez reactualizando profundos prejuicios coloniales respecto de los indígenas) en este caso, son "flojos" y "sucios". En la misma línea podemos interpretar el giro del programa Ingreso Ético Familiar, dejando apenas un piso mínimo de prestaciones garantizadas (Seguridades) y un más amplio espacio de transferencias económicas sujetas a condicionalidades (Oportunidades), es decir, al compromiso de demostrar "esfuerzos" y "logros" (Ministerio de Desarrollo Social Chile, 2013a).

Estrechamente conectado con el punto anterior, identificamos lo que denominamos infantilización. La idea a la base es que estas tecnologías de la vinculación afectiva y del condicionamiento mediante compromisos, también implican una representación infantilizante del sujeto de intervención. Esto tiene que ver, sobre todo, con el tipo de actitud paternalista que asumen, por mandato del diseño programático, los agentes de intervención directa, a través de estas técnicas de observación minuciosa de las dinámicas propias del hogar y el establecimiento de compromisos que asumen un perfil de sujeto no solo carenciado y colmado de rasgos negativos (flojo, sucio), sino también fuertemente incapaz de decisión sobre sus propias dinámicas familiares. La familia y, sobre todo la mujer-madre, que tiende a ser sobredemandada por estas políticas de intervención psicosocial, aparece como una figura infantilizada e incapaz, cuyos hábitos deben ser reforzados por el agente externo profundizando esta relación tutelar. La alimentación familiar, la administración del dinero, el cuidado de los hijos, el orden de la casa, la distribución de tareas domésticas, etc. aparecen como hábitos y tareas que el sistema familiar y la mujer-madre como principal responsable, serían incapaces de realizar autónomamente de acuerdo a sus propias dinámicas, y pasan a ser comportamientos vigilados y regulados por el agente externo, colonizando el espacio familiar y desvalorizando otras posibilidades de auto-organización y funcionamiento. Nuevamente, ninguna de estas funciones y dinámicas del sistema familiar es jamás observada ni problematizada institucionalmente en familias de los sectores económicos acomodados, con lo cual se refuerza la idea de que es la "familia pobre" el único

11 Corresponden a las preguntas número 14 y 16 de la Observación Psicosocial de Habitabilidad, específicamente del "Hábito a trabajar: asear y ordenar". Programa Puente Chile Solidario. 
espacio donde las dinámicas paternales, pautas de crianza, administración de los ingresos, etc. son visibilizadas como "problemas". Pero lo más llamativo es que el diseño de estas políticas obliga a que la familia intervenida acepte esta intromisión institucional, esta infantilización de sus integrantes responsables a cambio de la prioridad de la familia en diversas prestaciones sociales. "Ser familia Puente" y, posteriormente, "ser familia de Ingreso Ético Familiar", va de la mano con aceptar estas medidas de tutelaje y control cultural que se sostienen en profundos prejuicios étnicos y clasistas, que condiciona a las familias intervenidas a reconocerse como constitutivamente defectuosas, incompetentes y responsables de su propia condición de pobreza.

Mientras en el Programa Puente-Chile Solidario (Ministerio de Desarrollo Social Chile, 2008) se mantuvo este sesgo disciplinario e infantilizante tradicional para condicionar conductas en las familias "vulnerables", otros programas sociales para-estatales y estatales fueron introduciendo a través de líneas de capacitación, tecnologías directamente importadas desde el mundo de los negocios, en la línea del management/coaching social. Para las nuevas políticas sociales del emprendimiento ya no se trata tanto de disciplinar moralmente conductas en base a prejuicios respecto de los hábitos de las personas en situación de pobreza, sino que se abre toda una ventana de posibilidades para la "transformación positiva", lo "motivacional", las "capacidades", los "recursos", etc. es decir, habilidades blandas del sujeto indígena que no pueden ser burdamente disciplinadas, sino que deben estimularse a través del entrenamiento, el aprender haciendo, el acompañamiento experto, el atreverse a "hacer", mediado fundamentalmente a través de las conductas-proyecto (Bascopé-Julio, 2009; Navarrete-Saavedra, 2019). De este modo, la intervención del mediador o agente también requiere de ajustes, ya no se trata tanto de esta figura paternal y asistencial, sino de un tutelaje diferente, mucho más interactivo, orientado a que los sujetos aprovechen y desarrollen sus potencialidades y recursos para, por sí mismos, hacer frente a las condiciones de vulnerabilidad a través del emprendimiento.

Es en este marco que el tipo de relación entre el mediador y el individuo/ familia/comunidad intervenido comienza a adoptar rasgos propios del management empresarial y el coaching. En el caso de la intervención a nivel de "fortalecimiento organizacional", con decenas de capacitaciones para comunidades indígenas, asociaciones indígenas, agrupaciones de turismo étnico, grupos de emprendedores mapuche, etc. que son financiados por Orígenes o por otras vías de financiamiento desde el año 2000 y que son adjudicadas y ejecutadas por consultoras privadas, se va desplazando el tradicional estilo de trabajo de ONGs de desarrollo rural y sus formas de trabajo (diagnóstico rápido rural, técnicas participativas, educación popular, etc.) hacia estas nuevas capacitaciones orientadas al management organizacional. Se trata, finalmente, de una tecnología que busca la "transformación personal" de los destinatarios para mejorar los resultados económicos de la organización. Se trata de "movilizar los recursos de la población" y donde la "palabra clave es la motivación" (Van-Immerzeel, 2005, p. 51). 
Por ejemplo, el Programa Araucanía Tierra Viva, financiado por la Unión Europea u otros proyectos financiados por GTZ (Oficina de Cooperación Técnica Alemana) incorporan metodologías como "Aprender de los mejores", "Pachamama Raymi" o CEFE Competencybased Economies trough Formation of Entrepreneurs, traducida en español como "Desarrollo de Competencias para la Formación de Emprendedores", y se ha expandido en múltiples capacitaciones y proyectos por el mundo indígena a través de capacitaciones financiadas por Orígenes vía consultoras o programas de la cooperación extranjera. Para estas propuestas el problema no está en la falta de tierra y recursos económicos, sino en la "falta de incentivos", y la "escasez de conocimientos" (Van-Immerzeel, 2005). Podríamos resumir, simplificando, que estas nuevas tecnologías buscan entrenar a los sujetos para que sean capaces de definir metas, planificar y ejecutar acciones conducentes a dichas metas, abstrayendo al sujeto de cualquier disputa sobre injusticias y agravios históricos o distribución de recursos y oportunidades en la sociedad.

Un último rasgo de estas tecnologías de intervención, lo denominamos burocratización. Con esto queremos relevar el desplazamiento de tareas y actividades fuertemente asociadas al mundo de las instituciones y los funcionarios institucionales, hacia los destinatarios de las políticas sociales multiculturalistas. En términos muy coloquiales, podríamos resumir que se trata de "hacer trámites". Los trámites toman una relevancia llamativa para las nuevas políticas sociales, que podemos entender tanto desde el plano de la distribución de responsabilidades "hacia abajo", como desde el plano de "inversiones en el capital humano" de los propios sujetos. Con el caso del Programa Orígenes, por ejemplo, los dirigentes de las comunidades asumen una serie de responsabilidades en la gestión de los proyectos asociados al programa como efectuar cotizaciones de los materiales o productos que se pretenden adquirir, estar constantemente llamando al promotor asignado para averiguar el estado de "bajada de los recursos", realizar las compras, llevar registro de los gastos, hacer rendiciones con las boletas y facturas necesarias, etc. Esto además implica una gran cantidad de desplazamientos desde las comunidades rurales hacia los centros urbanos. En general, en los documentos programáticos estos "trámites" son entendidos como muestras necesarias del aumento en la implicación, la participación y la responsabilidad de las propias comunidades en las acciones para su desarrollo, mejorar las "capacidades de gestión" y el "surgimiento de liderazgos" (Ministerio de Desarrollo Social Chile, 2017b), pero lo que más nos interesa es el modo en que al promover este tipo de tareas y responsabilidades en los dirigentes se produce un desplazamiento desde lo político hacia lo burocrático. Es decir, en el espacio interno de la comunidad, la elección de los dirigentes y la valoración de sus funciones va cada vez más alejándose de una tarea de representación política y organización de los intereses de la comunidad y acercándose cada vez más a los rasgos propios de un funcionario institucional, que debe hacer trámites adecuadamente, en los tiempos determinados por las instituciones y en los formatos y modos definidos por éstas. Por lo tanto, dicha burocratización implica una re-organización de las funciones 
comunitarias y de su valoración, pues los nuevos dirigentes serán evaluados como exitosos en función de los recursos que puedan atraer a la comunidad a través de sus gestiones, su capacidad de formular proyectos y llevarlos a buen fin según las instituciones, y no por alguna valoración cultural interna, el respeto y mantención de prácticas de reciprocidad, la mediación en la resolución de conflictos, la sabiduría tradicional o cualquier otra función semejante.

Esta también es una forma de colonización de la comunidad por la racionalidad gubernamental en el sentido amplio, pues, aunque la propia comunidad asuma como necesarias estas funciones, no cabe duda de que han sido implantadas desde afuera por una racionalidad externa. De acá podemos inferir que la lógica de proyectos con las conductasproyecto ya mencionadas y las nuevas responsabilidades organizacionales y burocráticas trasladadas "hacia abajo", estarían tratando de alterar profundamente las relaciones de poder y estatus en el espacio comunitario, sin caer por esto en una visión esencialista de "comunidad tradicional"12. Las políticas sociales multiculturalistas neoliberales también intervienen en el espacio interno de la comunidad con efectos y objetivos claramente identificables: configurar el espacio comunitario en un código burocrático que sea compatible con el funcionamiento de la institucionalidad y el lenguaje de los proyectos neodesarrollistas, en clave multicultural.

\subsection{Puesta en valor}

Esta tendencia a la puesta en valor de "lo indígena" es característica de la última generación de políticas sociales multiculturalistas que germinan con el Programa Orígenes (administración de Ricardo Lagos) pero que alcanzan su máxima expresión y radicalidad con el Plan Araucanía y la primera administración de Sebastián Piñera (2010-2014). Es decir, son constitutivas de una nueva generación de políticas sociales de emprendimiento y desarrollo de competencias para competir en un entorno de oportunidades culturalmente sensibles, que vendrían a complementar y/o reemplazar a las políticas basadas en la protección de los grupos vulnerables. Guzmán (2003) desde Libertad y Desarrollo, el thinktank de la derecha, alentaba dicho giro señalando que "desde ópticas paternalistas se ha intervenido con cuerpos legales y políticas públicas que han exacerbado un enfoque protector que, más que habilitar a los miembros de las comunidades indígenas, los ha limitado" (p. 11).

12 Toda la legislación indígena del siglo XX ha intentado modelar la "comunidad indígena" para hacerla funcional a algún proyecto de desarrollo. Por ejemplo, la ley indígena del proyecto socialista de la Unidad Popular, si bien está basada en valores de solidaridad y en el reconocimiento de las injusticias históricas, también intenta modelar la "comunidad" promoviendo dinámicas propias de la organización campesina que buscaban la "democratización interna" de la comunidad (elección por votos del presidente y de la directiva, toma de decisiones por mayoría, etc.), bajo el supuesto de que la autoridad del longko representa una forma tradicional autoritaria de ejercicio del poder, incompatible con el proyecto socialista. 
Esta tecnología de puesta en valor de lo indígena involucra tres líneas de regulación que hemos denominado como desempoderamiento, diferenciación/competencia interna y etno-empresarialización. En el primer caso, con desempoderamiento nos referimos al gesto necesario que requieren las políticas sociales neoliberales que prometen dotar de más poder a los sujetos y comunidades, a través del fortalecimiento de sus potencialidades, capacidades, competencias y recursos. Pero para que el "empoderamiento" sea posible, es necesario primero institucionalmente producir al sujeto destinatario como "desactivado" y "carente de poder". Es decir, resultaría insensato destinar políticas cuyo objetivo es dotar de poder a los sujetos, si no existiera este gesto previo de observación y etiquetado institucional como desempoderado.

Este modelo implica una particular concepción del poder, que evita cualquier referencia a la naturaleza relacional y antagónica de las relaciones de poder social, en pos de una concepción del poder como "capacidad interna" que todos los individuos y grupos pueden desarrollar. No hay sujetos indígenas que sean históricamente "desempoderados" por la asimetría de las relaciones sociales en las cuales participan, incluyendo relaciones económicas, relaciones geopolíticas y epistémicas, sino que es su propia "pasividad" e “inactivación" la explicación fundamental. Por lo tanto, lo que hacen las políticas sociales centradas en el "empoderamiento" es necesariamente desempoderar, al menos como gesto institucional y cognitivo inicial indispensable de intervención. Este es el gesto primario y que da sentido a las posteriores tecnologías de desarrollo de competencias, motivación y entrenamiento conductual, que dicen contribuir al empoderamiento del sujeto. Y el objetivo de dichas intervenciones se enfoca en la "sensación subjetiva de poder" (Bröckling, 2015) y no algún cambio material en las relaciones de fuerza respecto de otros actores sociales e instituciones.

En segundo lugar, nos referimos a las tecnologías de regulación que denominamos de diferenciación/competencia interna. Dichas políticas operan concretamente tratando de producir una diferenciación socioeconómica entre los sujetos y familias al interior de las comunidades indígenas pues esto resulta fundamental para configurar condiciones de competencia que estimulen a los sujetos. Orígenes recomienda una "segmentación de los beneficiarios", distinguiendo entre "indígenas de edad adulta con bajos niveles de activos, además de bajo nivel de instrucción", de los "indígenas con aceptables niveles de activos y tierras" (Organización para la Agricultura y la Alimentación [FAO], 2011, p. 40). La lógica de proyectos y concursos busca sistemáticamente diferenciar entre los individuos, tratando de identificar a los más aptos de entre la masa y distribuir de este modo adecuadamente las recompensas que refuercen dichos comportamientos. Al asumir la lógica del proyecto concursable, la política social neoliberal instala el principio de que ya ni siquiera se trata de derechos y servicios para todos los sujetos "indígenas" focalizados, sino que existe un umbral de recursos y oportunidades a los que se accede meritocráticamente, a través de la 
competencia interna. Tanto las agencias estatales (FOSIS13, municipio, CONADI-Orígenes, etc.) como agencias y programas para-estatales (Araucanía Tierra Viva, ONGs, etc.), consagran la lógica del proyecto concursable, donde individuos o grupos deben competir por un fondo limitado de recursos para financiar sus propuestas. Estas tecnologías de intervención producen diferenciación interna, justamente donde la relativa igualdad y horizontalidad del mundo indígena rural es considerada un obstáculo para el funcionamiento de los mecanismos de competencia. Tampoco permiten que la comunidad, como espacio relativamente autónomo y reflexivo, pueda definir posibles destinatarios de los recursos en base a sus propios criterios y valoraciones, sino que son las bases de los concursos las que establecen el "perfil" del sujeto que resultará "recompensado" y son las propias instituciones las que evalúan y juzgan los méritos en cada caso.

Pero los proyectos concursables no son la única forma de promover la diferenciación y la competencia al interior del mundo comunitario indígena, pues otros programas como Orígenes o los PDTI (Programa de Desarrollo Territorial Indígena) de INDAP (Instituto de Desarrollo Agropecuario), lo hacen a través de políticas de selección y focalización propias. Orígenes, por ejemplo, en su primera etapa no tenía la intención de llegar a todas las comunidades indígenas sino focalizarse en algunas comunidades, a través de lo que se denominó “comunidades priorizadas" (Ley 19.949 de 2004). En este caso, Orígenes participó activamente en la diferenciación interna del mundo Mapuche y Aymará al invisibilizar unidades o formas de organización más amplias que la comunidad legalmente reconocida y al priorizar solo algunas comunidades dentro de espacios territoriales constituidos por varias comunidades. El programa no contaba (inicialmente) con ningún mecanismo para reconocer organizaciones territoriales indígenas de mayor alcance que la comunidad priorizada, fracturando en muchos casos la unidad organizacional de dichos territorios. Los PDTI implementados por INDAP en la gestión de Sebastián Piñera, por su parte, no contemplan ningún mecanismo para reconocer dinámicas organizacionales ni asociatividad, pues su foco es el comunero individual y su selección se realiza en base a criterios duros asignados por los propios dispositivos agrícolas y productivos, y por el puntaje en la ficha de protección social. De este modo, muchos espacios comunitarios y territoriales que se encontraban avanzando en iniciativas asociativas y territoriales, son nuevamente invisibilizadas por la política institucional, que no muestra interés en apoyar propuestas basadas en valores colectivistas e igualitarios, sino estimular la diferenciación interna y las lógicas de competencia.

13 FOSIS (Fondo de Solidaridad e Inversión Social) es creado junto con MIDEPLAN en 1990 y representa precisamente la primera iniciativa de los gobiernos de la postdictadura en esta lógica, al instalar la política de un fondo estable para asignar recursos de inversión social mediante proyectos concursables. Véase Ley 18.989 de 1990, Título II Del Fondo de Solidaridad e Inversión Social FOSIS. Mediante la misma ley, se establece la tercerización de la política social, creando un registro de personas naturales y jurídicas que pueden realizar contratos con dicho Fondo para implementar iniciativas de inversión social para la superación de la pobreza. 
Por último, para lograr esta puesta en valor resulta necesaria la etnoempresarialización del sujeto indígena. Las tecnologías neoliberales de intervención de la política social deben orientarse a producir efectivamente un perfil de sujeto indígena empresarial, como requisito indispensable para el desarrollo de las poblaciones indígenas focalizadas. Si bien se trata de una ruta que es posible identificar desde antes, es con el Programa Orígenes que se hace más nítida y, sobre todo, en la administración Piñera con el Plan Araucanía diseñado gerencialmente desde CorpAraucanía ${ }^{14}$ y las políticas sociales del Ministerio de Desarrollo Social, que la empresarialización toma un papel absolutamente protagónico en las tecnologías de gobierno del campo étnico y social. En el caso del Plan Araucanía, se trata de una "puesta en valor de lo mapuche" que involucra cada vez más no solo la tierra y elementos culturales, sino al propio sujeto indígena, interpelado como un "emprendedor mapuche" en potencia (Gobierno de Chile, 2010). El lenguaje empresarial de los clústeres territoriales, la incubación de negocios, los nichos de oportunidades, la innovación y gestión de empresas, etc. rebosa el lenguaje del Plan Araucanía (por ejemplo, se habla de un "plan habilitante" y un "motor productivo" a poner en marcha)15. Poco antes, Orígenes comenzó a hablar de fomentar la empresa indígena familiar y comunitaria, así como de valorar los activos tangibles e intangibles distintivos o exclusivos de los pueblos indígenas (FAO, 2011, p. 31). Libertad y Desarrollo habla del "emprendimiento con identidad como un gran potencial de desarrollo", destacando la gastronomía y el etnoturismo con enfoque de emprendimiento como algo fundamental para "mejorar la calidad de vida de los indígenas" (Libertad y Desarrollo, 2014) ${ }^{16}$. Las políticas sociales focalizadas son constitutivas de este proceso de promoción de la etnoempresa y el etnoempresario indígena, y comparten de ahora en adelante el mismo ADN de las iniciativas empresariales y el mundo de los negocios: un sujeto empresarial concebido como máquina de competencia que debe aprovechar un entorno de oportunidades (mercado). Acá la diversidad cultural, la tradición, los bienes simbólicos e inmateriales del mundo indígena pueden ser resignificados como "activos" intangibles para el emprendedor étnico en su trayectoria.

14 CorpAraucanía es una fundación privada que reúne a diversos dirigentes empresariales y de gremios productivos de la Región de La Araucanía, desde donde se elaboran una serie de diagnósticos sobre el "atraso regional" y las políticas pro-empresariales necesarias para sacar a la región de la posición que ocupa como la más pobre del país. Durante ambas administraciones de Sebastián Piñera y la derecha, tanto las autoridades regionales como las líneas de acción del gobierno local han salido directamente desde las oficinas de la corporación.

15 En el segundo y actual gobierno de Sebastián Piñera se reemplaza el Plan Araucanía, promovido en su primera administración, por el denominado Plan Impulso Araucanía que, nuevamente, evita el lenguaje del reconocimiento y los derechos, para centrarse en propuestas desarrollistas y productivistas.

${ }^{16}$ El Instituto Libertad y Desarrollo destaca, por ejemplo, la experiencia de 7 emprendedores de origen mapuche que tuvieron la posibilidad de visitar Sillicon Valley para "ver cómo funcionan las empresas más innovadoras del mundo y mostraron sus respectivos proyectos" (Libertad y Desarrollo, 2014). 


\section{Conclusiones}

Sostenemos que estos 4 conjuntos de estrategias de regulación: marcaje, domesticación, tutela y puesta en valor, junto con sus formas y efectos específicos, dan cuenta de un rol mucho más protagónico de la política social chilena en el gobierno de las poblaciones indígenas del que habitualmente se les reconoce. La política social del multiculturalismo neoliberal no puede reducirse a simple asistencialismo -paliativos frente a situaciones urgentes de necesidad fortaleciendo vínculos clientelares con la comunidadcomo a veces se acusa, incluso desde el propio mundo indígena. Pero tampoco se trata de una conquista de la sociedad frente al Estado, un avance de derechos, bienes y servicios de los cuales el mundo indígena ha estado excluido, a modo de herramienta de redistribución. Más bien, estas políticas son constitutivas del multiculturalismo en cuanto nueva racionalidad de gobierno de las poblaciones en clave étnica y en cuanto modo de subjetivación, produciendo perfiles de ciudadanos para el proyecto neoliberal. Es a través de estas modalidades cotidianas de intervención que se invisibilizan las causas históricoestructurales de la pobreza indígena y se refuerzan entramados discursivos que posicionan la vulnerabilidad intrínseca y la falta de activación de capacidades del propio sujeto, alentando nuevas generaciones de políticas despolitizadoras y psicologizantes (NavarreteSaavedra, 2019).

Nos permiten, además, dar cuenta de cómo las primeras políticas multiculturalistas que estaban ancladas en una lógica de protección de los vulnerables estarían compitiendo o complementándose con nuevas generaciones de políticas basadas en el emprendimiento y la producción del empresario étnico. Este proceso implica una reactualización de las dinámicas de colonialidad y nuevas demandas para los agentes de intervención (profesionales de las ciencias sociales). Respecto del patrón de colonialidad, en la nomenclatura de Quijano, podemos ver cómo ciertas tecnologías de marcaje, domesticación y tutelaje refuerzan representaciones coloniales que limitan la capacidad de agencia de los sujetos etiquetados como indígenas y los visibiliza como carentes, incapaces, anclados en el pasado y necesitados de intervención. Pero con las estrategias de puesta en valor o con modos de tutela de management/coaching social, propios de este nuevo régimen del etnoemprendimiento, evidenciamos una reorganización de la colonialidad. Acá la colonialidad no tiene que ver tanto con los prejuicios coloniales burdos de la inferiorización del sujeto indígena, sino con el nuevo imperativo de "activarse", "ponerse en valor" y enfrentar un escenario de competencia y oportunidades en un mercado étnicamente sensible. Más que un sujeto intrínsecamente atrasado, el indígena aparece como un sujeto que, por su diferencia cultural y por la inadecuación de las tecnologías de gobierno (mal gobierno), no ha sido adecuadamente activado para el desarrollo. Esta colonialidad ya no se ejerce a través de una fuerza que subordina, discrimina y normaliza la diversidad intolerable de los cuerpos y poblaciones, sino que aparece como un mandato para que los 
sujetos se hagan cargo de sí mismos y resignifiquen la identidad indígena, la tradición, las relaciones comunitarias, etc. como activos intangibles para el emprendimiento.

$\mathrm{Y}$, respecto de los agentes de intervención, estas nuevas estrategias y regulaciones conllevan nuevas demandas para los profesionales. Estas tienen que ver con 3 tipos: primero, con las tecnologías de emprendimiento y empresarialización del sujeto indígena, las que requieren de profesionales con un perfil mucho más cercano al mundo de los negocios y la gestión organizacional; esta especie de management/coaching étnico, necesario para activar, motivar y entrenar a los sujetos en su trayectoria hacia el emprendimiento. En segundo lugar, se trata de demandas que tienen que ver con la conexión del sujeto de intervención con los dispositivos sociales y las oportunidades del entorno. Acá el agente debe ser una especie de "bisagra", que facilite el vínculo entre los sujetos y las redes de servicios y derechos sociales (en las políticas de la vulnerabilidad) y/o con las fuentes de proyectos y oportunidades (en las políticas del etnoemprendimiento). Por último, hay algunas tecnologías de intervención que requieren de un papel de intervención directa, cara a cara, para ofrecer contención, apoyo psicosocial y reforzar valores en los sujetos destinatarios. Lo que desaparece en estas 3 funciones es el carácter problematizador y crítico del agente de intervención social, rasgo fundamental de las tradiciones latinoamericanas de acción social (educación popular, I-A-P, amplificación sociocultural, etc.).

Esta tipología de regulaciones y efectos que la política social promueve respecto de sus destinatarios indígenas en ningún caso pretende ser la única lectura posible, pero permite, a partir de un trabajo de revisión extenso y sistemático, dar cuenta de algunos rasgos que evidencian la particular racionalidad neoliberal que subyace al multiculturalismo de la posdictadura chilena. Y, si bien en rigor solo se refieren a la experiencia chilena, pueden servir para pensar otros escenarios y contextos latinoamericanos. Esto con sus respectivos recaudos, pues mientras por un lado el neoliberalismo chileno cuenta con varios años de ventaja respecto de sus vecinos regionales y sigue siendo el experimento más radical y extremista, por otro lado, el multiculturalismo oficial ha sido mucho más conservador, extremadamente pobre en el reconocimiento de derechos colectivos y menos progresista que en el resto de la región ${ }^{17}$.

No ha sido la intención de este trabajo desconocer los avances en reducción de la pobreza indígena que se pueden observar en postdictadura chilena. Los datos duros disponibles gracias a la CASEN y al INE evidencian una reducción importante en la cifra de pobreza, no obstante, ésta sigue siendo mayor en la población indígena que en la población no indígena. Lo que nos interesa es problematizar la estrategia de gubernamentalidad étnica

17 Incluso habría que señalar las aristas selectivamente punitivas del multiculturalismo chileno de la postdictadura, donde sistemáticamente se ha perseguido y criminalizado al movimiento mapuche en el centrosur del país. 
que ha priorizado reducir la "cuestión étnica" a un asunto de pobreza indígena rural, suprimiendo otras aristas de reconocimiento de derechos, empoderamiento político y restitución territorial. Bajo la excusa del combate a la pobreza, las políticas sociales multiculturalistas también están imponiendo nuevas formas de regular y administrar la etnicidad y perfilar un sujeto indígena "desde arriba". Tampoco es posible desconocer el papel de la política social multiculturalista dentro de un escenario mayor de conflictividad social y respuestas estatales represivas ${ }^{18}$.

Someter a análisis crítico el entramado de dispositivos y tecnologías de intervención social en las cuales participamos -ya sea como agentes directos, como formadores de futuros profesionales o como investigadores- resulta importante sobre todo si creemos que es necesario disputar el espacio de la política social e ir más allá de sus funciones de marcaje, domesticación, tutela y puesta en valor, para reinscribirlas dentro de un proyecto de interculturalidad crítica y aspiración descolonizadora.

\section{Referencias bibliográficas}

Álvarez-Leguizamón, S. (2002). La Pacificación de la multiculturalidad globalizada, recomposición de campos del saber y nuevas formas de intervención social. En B. LorenteMolina y C. V. Zambrano (Eds.), Estudios introductorios en relaciones interétnicas (pp. 309342). Bogotá, Colombia: Universidad Nacional de Colombia.

Álvarez-Leguizamón, S. (2011). Gubernamentalidad neoliberal y focopolítica en América Latina: los programas de transferencia condicionadas ¿políticas de cohesión social con los pobres? En C. Barba-Solano (Ed.), Perspectivas críticas sobre cohesión social: desigualdad y tentativas fallidas de integración en América Latina (pp. 251-258). Buenos Aires, Argentina: CLACSO.

Assies, W. (2006). Prologo. En N. Yáñez y J. Aylwin (Eds.). El gobierno de Lagos, los pueblos indígenas y el "nuevo trato": las paradojas de la democracia chilena (pp. 4-8). Santiago: Observatorio de derechos de los pueblos indígenas, Fundación Ford, IWGIA.

Bascopé-Julio, J. (2009). La invasión de la tradición. Lo mapuche en tiempos culturales. Guatemala-Santiago de Chile: ICAPI-CoLibris.

Boccara, G. (2007). Etnogubernamentalidad. La formación del campo de la salud intercultural en Chile. Chungará Revista de Antropología Chilena, 39(2), 185-207.

Boccara, G., y Bolados, P. (2010). ¿Qué es el multiculturalismo? La nueva cuestión étnica en el Chile neoliberal. Revista de Indias, 70(250), 651-690.

18 Podríamos decir, siguiendo a Wacquant (2015), que la política social representa el brazo izquierdo y la política punitiva el brazo derecho de la gubernamentalidad neoliberal, que se imbrican y complementan para regular a las mismas poblaciones (pobres, minorías étnicas, inmigrantes, etc.). Esto resulta particularmente pertinente para el caso Mapuche en Chile, tal como Hale \& Millaman (2005), Toledo-Llancaqueo (2007) o ZapataSilva (2019) han evidenciado, se trata del complemento entre una política punitiva y represiva (Operación Paciencia, Operación Huracán, Comando Jungla, etc.) con políticas sociales selectivas (Orígenes, Chile Indígena, Plan Araucanía, Plan Impulsa Araucanía, etc.). 
Navarrete-Saavedra

Bröckling, U. (2015). El self emprendedor. Sociología de una forma de subjetivación. Santiago: Ediciones Universidad Alberto Hurtado.

Chile Travel. (2014). Pueblos originarios y etnoturismo. Recuperado de https:/ / chile.travel/que-hacer/cultura/pueblos-originarios-y-etnoturismo.

Corona, S., y Kaltmeier, O. (2012). En diálogo: metodologías horizontales en ciencias sociales y culturales. Barcelona, España: Gedisa.

Flick, U. (2012). Introducción a la investigación cualitativa. Madrid, España: Morata.

Flick, U. (2014). La gestión de calidad en investigación cualitativa. Madrid, España: Morata.

Foucault, M. (2012). Nacimiento de la biopolitica. Buenos Aires, Argentina: Fondo de Cultura Económica.

Gobierno de Chile. (13 de julio de 1990). Ley Orgánica del Fondo de Solidaridad e Inversión Social, FOSIS [Ley 18.989 de 1990].

Gobierno de Chile. (17 de mayo de 2004). Sistema de protección social para familias en situación de extrema pobreza denominado "Chile Solidario". [Ley 19.949 de 2004].

Gobierno de Chile. (2010). Plan Araucanía: Invirtiendo en Personas y Oportunidades. Temuco: Gobierno de Chile.

Gobierno de Chile. (28 de septiembre de 1993). Ley Indígena. [Ley 19.253 de 1993].

Guzmán, E. (Ed.). (2003). La cuestión mapuche: aportes para el debate. Santiago, Chile: Fundación Libertad y Desarrollo.

Hale, C. (2004). Rethinking indigenous politics in the Era of the Indio Permitido. NACLA Report on the Americas, 38(2), 16-21.

Hale, C., \& Millaman, R. (2005). Cultural Agency and Political Struggle in the Era of Indio Permitido. En D. Sommer (Ed.), Cultural Agency in the Americas (pp. 281-301). Durham, Estados Unidos: Duke University Press.

Huinca-Piutrin, H. (2012). Los Mapuche del Jardín de Aclimatación de París en 1883: objetos de ciencia colonial y políticas de investigación contemporáneas. En H. Nahuuelpan, H. Huinca, P. Mariman, L. Cárcamo, M. Mora, J. Quidel... A. Cuyul, Ta iñ fijke xipa rakizuameluwün. Historia, colonialismo y resistencia desde el país Mapuche (pp. 89-117). Temuco: Ediciones Comunidad de Historia Mapuche.

Illanes, M. (2007). Cuerpo y sangre de la política. La construcción histórica de las Visitadoras Sociales (1887-1940). Santiago, Chile: LOM Ediciones.

Instituto Nacional de Estadísticas Chile. (2005). Estadísticas Sociales de los pueblos indígenas en Chile. Censo 2002. Santiago, Chile: INE, Programa Orígenes MIDEPLAN-BID.

Lautier, B. (2008). Las lecciones del debate sobre la universalización de la protección social en América Latina (una relativización de la especificidad chilena). En M. de Cea, P. Díaz y G. Kerneur (Eds.), Chile: ¿De país modelado a país modelo? Una mirada sobre la política, lo social y la economía. Santiago: GRESCH, ICSO, UB, Universidad de Chile.

Laval, C. y Dardot, P. (2013). La nueva razón del mundo. Ensayo sobre la sociedad neoliberal. Barcelona: Gedisa.

Libertad y Desarrollo. (2014). La Araucanía. Emprendimiento con identidad. Recuperado de https://lyd.org/centro-de-prensa/noticias/2014/07/la-araucania-emprendimiento-conidentidad/. 
Ministerio de Desarrollo Social Chile. (2008). Observación Psicosocial de Habitabilidad. Programa Puente-Chile Solidario. Chile: Ministerio de Desarrollo Social.

Ministerio de Desarrollo Social Chile. (2012). Informe de Politica Social 2012. Chile: Ministerio de Desarrollo Social.

Ministerio de Desarrollo Social Chile. (2013a). Informe de Política Social 2013. Chile: Ministerio de Desarrollo Social.

Ministerio de Desarrollo Social Chile. (2013b). Monitoreo de Programas Sociales. Subsecretaría de Evaluación Social. División de políticas Sociales. Chile: Ministerio de Desarrollo Social.

Ministerio de Desarrollo Social Chile. (2017a). CASEN 2015. Pueblos indígenas. Sintesis de resultados. Chile: Ministerio de Desarrollo Social. Recuperado de http:/ / observatorio.ministeriodesarrollosocial.gob.cl/casenmultidimensional/casen/docs/CASEN_2015_Resultados_pueblos_indigenas.pdf.

Ministerio de Desarrollo Social Chile. (2017b). Informe Final Programa Chile Indígena. Chile: Ministerio de Desarrollo Social, Corporación Nacional de Desarrollo Indígena. DIPRES.

Ministerio de Desarrollo y Planificación-Corporación Nacional de Desarrollo Indígena (2010). Informe Final de Evaluación. Programa de Desarrollo Indígena MIDEPLAN-BID-Orígenes Fase II. Recuperado de https://www.dipres.gob.cl/597/articles-141177_informe_final.pdf.

Ministerio de Planificación y Desarrollo, y Banco Interamericano de Desarrollo. (2001). Documento Contrato de Préstamo No 1311/OC- CH entre la República de Chile y el Banco Interamericano de Desarrollo. Programa multifase de Desarrollo Integral de Comunidades Indígenas. MIDEPLAN-BID, primera Fase. Chile: MIDEPLAN-BID.

Murillo, S. (2008). Producción de pobreza y construcción de subjetividad. En A. Cimadamore y A. Cattani (Coords.), Producción de pobreza y desigualdad en América Latina (pp. 41-78). Bogotá, Colombia: Siglo del Hombre Editores.

Nahuelpán, H. (2013). El lugar del "indio" en la investigación social. Reflexiones en torno a un debate político y epistémico aún pendiente. Revista Austral de Ciencias Sociales, (24), 71-91.

Navarrete-Saavedra, R. (2015). El multiculturalismo chileno y el estudio de sus políticas: algunas tensiones desde una investigación en curso. Praxis, Revista de Psicología, (27), 41-60.

Navarrete-Saavedra, R. (2018). La pobreza indígena en el discurso del Banco Mundial. Revista Hallazgos, 15(30), 79-97.

Navarrete-Saavedra, R. (2019). Las políticas sociales en el régimen del etnoemprendimiento. Discursos y trayectorias posibles para el destinatario mapuche. Cultura-hombresociedad, 29(1), 162-190.

Organización para la Agricultura y la Alimentación. (2011). Aprendizajes de las metodologías utilizadas por dos experiencias de atención a comunidades indígenas: FAO - CONADI y Programa Orígenes.

Powell, J., \& Steel, R. (2012). Policy, governmentality and governance. JOAAG, 7(1), 1-10.

Quijano, A. (2000). Colonialidad del poder: eurocentrismo y América Latina. En E. Lander (Comp.), La colonialidad del saber: eurocentrismo y ciencias sociales. Perspectivas latinoamericanas (pp. 201-246). Buenos Aires: CLACSO. 
Navarrete-Saavedra

Raczynski, D. (Ed.). (1994). Estrategias para combatir la pobreza en América Latina: programas, instituciones y recursos. Santiago, Chile: CIEPLAN, Banco InterAmericano de Desarrollo. Recuperado de https://publications.iadb.org/publications/spanish/document/Estrategiaspara-combatir-la-pobreza-en-Am\%C3\%A9rica-Latina-Programas-instituciones-yrecursos.pdf.

Ramírez, J. (2015). Conflicto mapuche: una visión general. Recuperado de https:/ /lyd.org/wpcontent/uploads/2016/02/Serie-Informe-Poli\%CC\%81tico-149.pdf.

Rapley, T. (2014). Los análisis de la conversación, del discurso y de documentos en Investigación Cualitativa. Madrid: Morata.

Restrepo, E. (2012). Intervenciones en teoría cultural. Popayán: Editorial Universidad del Cauca.

Richards, P. (2016). Racismo: el modelo chileno y el multiculturalismo neoliberal bajo la Concertación 1990-2010. Santiago, Chile: Pehuén.

Rojas-Lasch, C. (2012). Gobernar la extrema pobreza: un análisis del dispositivo de intervención Chile Solidario-Puente. En V. Lemm (Ed.), Michel Foucault: neoliberalismo y biopolítica (pp. 51-84). Santiago, Chile: Universidad Diego Portales.

Spink, M., y Menegon, V. (2006). Prácticas discursivas como estrategias de gubernamentalidad: el lenguaje de los riesgos en documentos de dominio público. En L. Íñiguez (Ed.), Análisis del discurso. Manual para las ciencias sociales (pp. 197-230). Barcelona, España: Editorial UOC.

Toledo-Llancaqueo, V. (2007). Prima Ratio. Movilización mapuche y política penal. Los marcos de la política indígena en Chile 1990-2007. Revista OSAL, (22), 253-276.

Tuhiwai-Smith, L. (2016). A descolonizar las metodologías. Investigación y pueblos indígenas. Santiago, Chile: LOM ediciones.

Tuider, E. (2012). Contando historias/narraciones en un contexto postcolonial. Análisis del discurso y análisis biográfico como métodos horizontales. En S. Corona y O. Kaltmeier (Eds.), En diálogo. Metodologías horizontales en Ciencias Sociales y Culturales (pp. 111-135). Barcelona: Gedisa.

Van-Immerzeel, G. (2005). Aprender de los mejores. "Manual de Campo". Temuco, Chile: Unión Europea; Araucanía Tierra Viva; Gobierno de Chile.

Vasilachis de Gialdino, I. (2006). La investigación cualitativa. En I. Vasilachis de Gialdino (Coord.). Estrategias de investigación cualitativa (pp. 23-60). Barcelona: Gedisa.

Wacquant, L. (2015). Marginalidad, etnicidad y penalidad en la ciudad neoliberal: una cartografía analítica. En M. Castillo y C. Maldonado (Eds.), Desigualdades. Tolerancia, legitimación y conflicto en las sociedades latinoamericanas (pp. 183-214). Santiago: RIL Editores.

Zapata-Silva, C. (2019). La crisis del multiculturalismo. Conflictividad social y respuestas críticas desde el pensamiento político indígena. Alemania: CALAS, Editorial Universidad de Guadalajara. 


\section{OTROS ARTÍCULOS DE PROSPECTIVA No. 31 DE 2021}

\section{PRESENTACIÓN}

Presentación. Reflexiones sobre desafios al publicar sistematizaciones

Rosa María Cifuentes-Gil

\section{EDITORIAL}

Reflexiones sobre Trabajo Social: aportes de la Sistematización

María Rocío Cifuentes-Patiño

\section{ARTÍCULOS}

Hacer lo que se sabe, pensar lo que se hace. La sistematización como modalidad investigativa Alfonso Torres-Carrillo

Aportes y desafios de la Sistematización de experiencias en el Trabajo Social y la extensión crítica. Apuntes y reflexiones desde la perspectiva de la Educación Popular

María Rosa Goldar

Valeria Chiavetta

La sistematización en Trabajo Social y la epistemología feminista del punto de vista. Diálogos sobre la producción de conocimiento sustentada en experiencias

Ruth Noemí Parola

María Florencia Linardelli

La Sistematización investigativa de las experiencias: del baile de los que sobran a la fiesta de los que faltan

María Belén Ortega-Senet

Sistematización y Trabajo Social en Chile. El largo y sinuoso camino

Patricia Lorena Castañeda-Meneses

Ana María Salamé-Coulon
Sentipensar la pandemia COVID-19 desde la sistematización de la experiencia en Trabajo Social: reflexiones del profesor Oscar Jara Holliday

Elia Sepúlveda-Hernández

La sistematización de experiencias, una investigación social cualitativa que potencia buenas prácticas de convivencia y gobierno. La experiencia de un conjunto residencial multifamiliar en Cali, Colombia Martha Lucia Echeverry-Velásquez Manuela Prada-Dávila

Construcción de subjetividades epistemológicaspolíticas de profesoras y profesores de Investigación social en una universidad privada y confesional en Bogotá

Giovanni Mora-Lemus

Sistematización de la experiencia Reconocimiento de los derechos humanos del adulto mayor en dos familias residentes en Cali y Valledupar (Colombia)

Lina María Cuello-Lacouture

Jimena del Pilar Jaramillo-Jaramillo

La memoria transformadora como estrategia de intervención profesional en los procesos de reconciliación social: comprensión a partir de mujeres campesinas, excombatientes y jóvenes en Manizales, Colombia

Yeimmy Stephania Corredor-Sotelo

Juliana Fuertes-Fuertes

Sistematización de una estrategia de educación informal implementada en personas privadas de la libertad en el establecimiento penitenciario de mediana seguridad y carcelario de Barranquilla, Colombia

Rafael Humberto Herrera-Mercado Rafael Alberto Zambrano-Vanegas 
Aportes significativos del proceso de intervención comunitaria con la Escuela Popular de Comunicación Alternativa Jaime Garzón de la ciudad de Cúcuta, Colombia

Carlos Lasso-Urbano

La sistematización de la intervención como metodología de investigación en Trabajo Social. Importancia práctica y teórica de la fase de recogida de datos en la intervención social según experiencia del Programa de Apoyo a las Familias en Zaragoza, España

Elisa Esteban-Carbonell

Nuria Del Olmo-Vicén

Papel de la sistematización de experiencias en los procesos de evaluación de intervenciones de salud pública en la Comuna Saludable por la Paz, Cali - Colombia

Jenny Faisury Peña-Varón

Paola Andrea Marín-Velásquez

Janeth Mosquera-Becerra

Experiencia de intervención social en hogares comunitarios integrales del barrio Alfonso Bonilla Aragón, Cali - Colombia

Julián Alexander Montaño-Cárdenas

Las políticas sociales y el gobierno de la "población indígena". Estrategias y regulaciones en el multiculturalismo chileno

Rodrigo Agustín Navarrete-Saavedra

Representaciones sociales sobre estilo de autoridad y tipos de interacción en cuidadores de residencias de protección infantil en Chile

Marcelo Gallegos-Fuentes
Carmen Gloria Jarpa-Arriagada

Reflexiones sobre inseguridad social y cuestiones penales. Una respuesta estratégica a partir de experiencias de cooperativismo con ex detenidos en Argentina

Analia Elizabeth Otero

Yael Yanina Barrera

Desarrollo y salud: la emergencia de un nuevo paradigma

Jesús María Sánchez-Ordóñez

Trabajo Social en ejercicio libre: la perspectiva profesional en España

Paula Frieiro-Padín

Tamara Fernández-Arias

Rubén González-Rodríguez

\section{RESEÑAS}

Social Work and the City: Urban Themes in 21stCentury Social Work

Felipe Saravia-Cortés

Respuestas del Trabajo Social ante emergencias sociales y problemáticas sociales complejas de México y España

Felipe Saravia-Cortés

El feminismo, el género y la profesionalización del trabajo social en Colombia (1936-2004)

Ambar Oriana Serna-Lombo

El puño invisible. Arte, revolución y un siglo de cambios culturales

Carlos Arturo Robledo-Marín

\section{PROSPECTIVA}

No. $31 \bullet$ ene.-jun. 2021

e-ISSN: 2389-993X • Universidad del Valle 